\title{
The Navy's Best Practices Approach to Reliability and Quality
}

\author{
W. J. Willoughby Jr., Director \\ Reliability, Maintainability \& Quality Assurance \\ Office of Assistant Secretary of the Navy, Shipbuilding \& Logistics
}

Key Words - Quality; Design analysis; Test analyze and fix; Piece part contol; Defect control.

Reader Aids -

Purpose: Present the Navy's perspective on acquisition or upgrading of weapon systems

Special math needed for explanations: None

Special math needed to use results: None

Results useful to: Management, Design engineers, Manufacturing engineers, R\&M analysts, Production specialists

\begin{abstract}
For the first time in recent history, the US Army, Navy, and Air Force are in fundamental agreement on the priority of reliability in their weapon system requirements. Even more significant is mutual recognition that reliability is achieved not by setting numerical requirements and testing for compliance, but by focusing on the fundamentals of design and manufacturing; and that quality is achieved not by counting defects but by eliminating their causes. These lessons, long in coming to the Department of Defense and its contractors, are now beginning to be implemented in the acquisition or upgrading of most weapon systems. A major impetus to implementation was the 1982-83 work of the Defense Science Board Task Force on the Transition from Development to Production, which led to DoD Directive 4245.7, its companion DoD Manual 4245.7-M, and Department of Defense Advocacy. Each service is taking a somewhat different approach to the implementation of these similar new initiatives. The purpose of this paper is to outline the Navy's approach, for comparison with the initiatives of the other services.
\end{abstract}

\section{INTRODUCTION}

To begin, the Navy is focusing on design and manufacturing risk associated with the transition from development to production, in order to establish technical balance with administrative risk (emphasized by current DoD major system acquisition policy). This transition is not a discrete event occurring at a specific milestone in the acquisition schedule but rather a continuum of the necessary activities beginning before full-scale development and continuing throughout manufacturing. The Navy is interested in the technical issues of design, test, and production which are the causes of cost and schedule overruns and performance shortfalls, rather than the overruns and shortfalls themselves with which the Defense System Acquisition Review Council decision-making process has been concerned. While many talk about this transition process and production readiness in the same breath, the latter is only one of some 50 areas of risk requiring attention. That is, production readiness is a very small subset of the transition process.

DoD Manual 4245.7-M, identifies the most critical areas of risk affecting the transition from development to production - the critical path for a material acquisition program. For each area, the Manual contains a template which describes why the risk exists and outlines what can be done to reduce it. To provide detailed guidance for implementation, we borrowed key technical executives from several of the companies represented on the DSB Task Force. Combining their knowledge with our in-plant experience involving several hundred material acquisition programs, they and we compiled a new document describing, for each template, proven best practices for reducing risk. This "Best Practices Manual" (NAVSO P-6071, available from the US Government Printing Office) has the subtitle "How to avoid surprises in the world's most complicated technical process," high-technology weapon systems.

\section{BEST PRACTICES APPROACH}

Since the typical reader is associated with reliability and quality in his or her organization, let's look at some specifics of the Best Practices approach to Navy weapon systems. The critical path templates - those areas of risk which account for virtually all cost, schedule, and performance shortfalls in current systems - are shown in figure 1. Those treated in this article fall into the engineering areas of design, test and production. And I emphasize that each describes best practices found in industry wherever they are in use and have proven their effectiveness above all other known approaches to the same problem. To provide a little insight on the nature of these templates, I discuss design analysis; test, analyze and fix; piece part control; and defect control:

- Design Analysis. This template addresses the analysis required to reduce design risk to a minimum. Best practice requires that the designers conduct their own analyses to assure that no parts are overstressed, even under the worst combinations of environments specified by requirements, and that if the design includes semiconductors, no junction temperatures exceed $110^{\circ} \mathrm{C}$. There must be no sneak circuits which, under certain conditions (but without part failure) can allow untoward events to occur. And the effects of failure modes must be known and acceptable; otherwise, redesign is required. Reliability math models and predictions are not among the best practices.

- Test, Analyze, and Fix. Many development contracts did not include reliability development testing, relying 


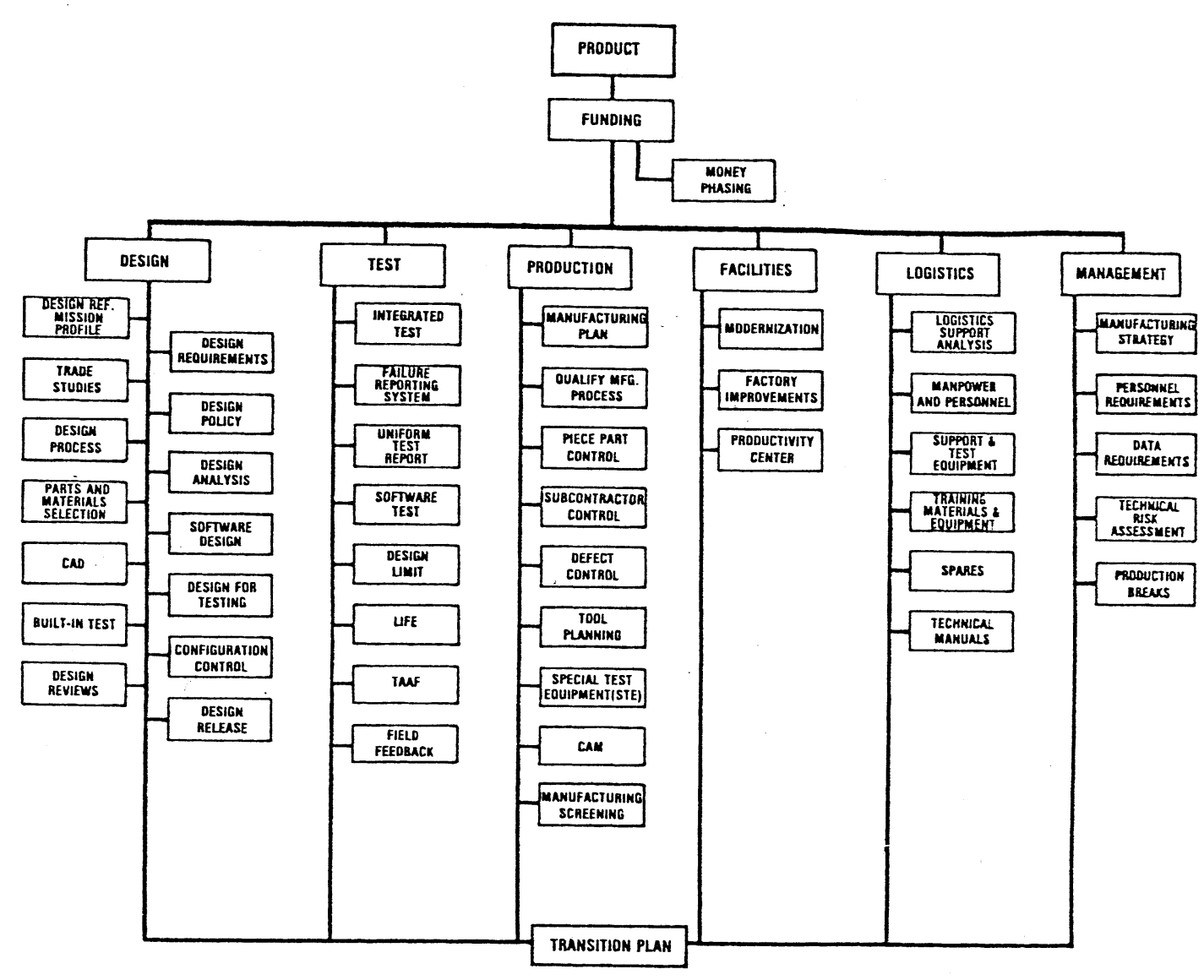

Fig. 1. Critical Path Templates

instead on a reliability qualification test (rel demo) to demonstrate a numerical MTBF requirement. The former is an in-line design tool while rel demo is an after-the-fact management tool. Reliability demostration has been ineffective in providing weapon systems with acceptable field reliabilities - it is not a best practice. Reliability development (TAAF) testing using simulated mission profile environments and emphasizing reliability growth has proven to be a vastly more effective use of limited test resources.

- Piece Part Control. Most military require the use of military standard parts in weapon and support systems. This policy, although better than using commercial parts, leaves much to be desired in its ability to ensure delivery of high quality and reliable parts. Industry has found that $100 \%$ environmental stress re-screening of semiconductor parts is a highly cost-effective best practice, both from the contractor and the Government viewpoints. I have visited contractors having more than $50 \%$ of their production in rework due to faulty parts. A major reduction in defective parts before first use goes a long way toward reducing or even eliminating this hidden factory (the rework and repair side of factory operations), and the cost savings in early detection of defects is substantial. The Navy advocates a limit of 1 defect per $10^{4}$ semiconductor piece parts, and figure 2 shows why. A low yield and a busy factory result from a lesser requirement for typical Navy hardware; the $2 \%$ Lot Tolerance Percent Defective of the past is totally unacceptable. The Navy's aim is: First Time Turn-On Success!
- Defect Control. On my visits to hundreds of contractor facilities over the years I have seen countless systems for tracking manufacturing defects. The system I have found to be most effective for management oversight of quality includes but three types of data or charts: defect history, defect distribution, and defect reduction. Sample charts are shown in figures 3-5. Defect history illustrates the number of defects per item by serial number or date-ofmanufacture sequence. It clearly flags not only general trends toward improvement but also production line problems in adjacent units produced. The Gantt-type defect distribution chart identifies the types of defects by category and percentage occurrence.

Defect reduction data tracks the average number of defects per unit by cumulative number of units produced, to measure quality growth or the learning curve in the manufacturing process. With vigorous control of the causes of defects, these data tend to follow a straight line on a log-log chart, and its downward slope can be used as a measure of defect management. The learning curve concept, which has been around since the 1930s, can be used to compare quality growth in a program today to that of any other program where similar data were kept. This provides an excellent indicator as to whether or not defect management initiatives are meeting reasonable expectations in a given program. 


\begin{tabular}{|c|c|c|c|c|c|c|}
\hline & \multicolumn{5}{|c|}{ NUMBEF OF PARTS ON BOARD } \\
\hline & & 50 & 100 & 200 & 300 & 400 \\
\hline \multirow{2}{*}{ 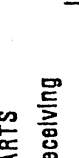 } & $97 \%$ & $21.8 \%$ & $4.8 \%$ & $0.26 \%$ & $0.01 \%$ & $0.005 \%$ \\
\hline & $98 \%$ & $36.4 \%$ & $13.3 \%$ & $1.8 \%$ & $0.23 \%$ & $0.03 \%$ * \\
\hline \multirow{3}{*}{ 总音 } & $99 \%$ & $60.5 \%$ & $36.6 \%$ & $13.4 \%$ & $4.9 \%$ & $1.8 \%$ \\
\hline & $99.9 \%$ & $95.1 \%$ & $90.5 \%$ & $81.9 \%$ & $74.1 \%$ & $67.0 \%$ \\
\hline & 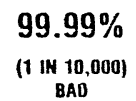 & $99.5 \%$ & $99.0 \%$ & $98.0 \%$ & $97.0 \%$ & $96.0 \%$ \\
\hline
\end{tabular}

Fig. 2. Effect of Bad Parts on Circuit-Board Yield

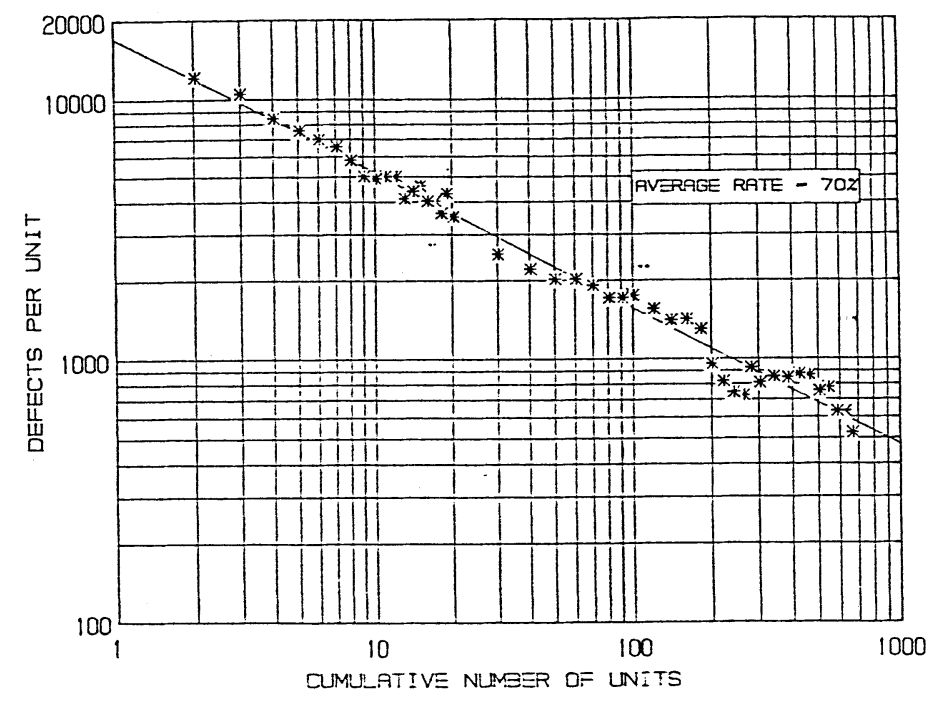

Fig. 5. Defect Reduction

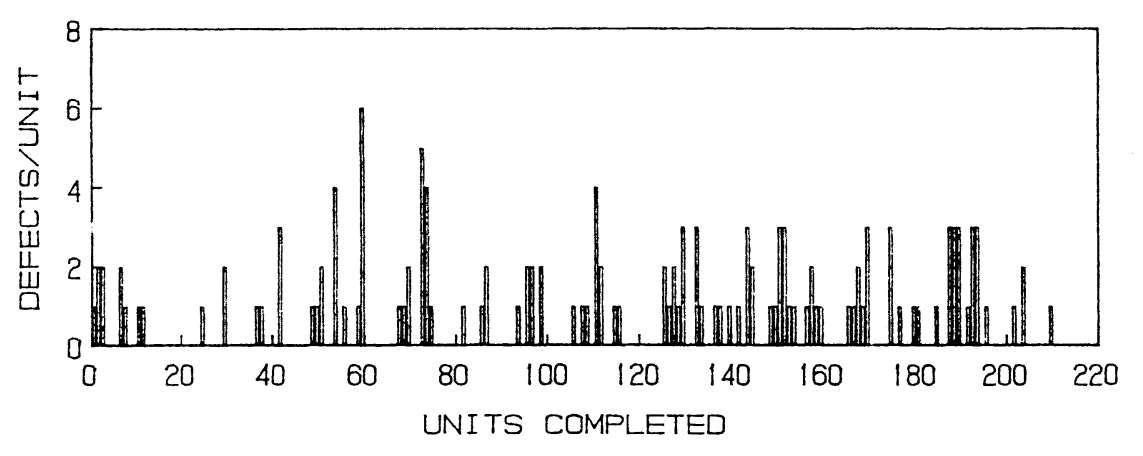

Fig. 3. Defect History

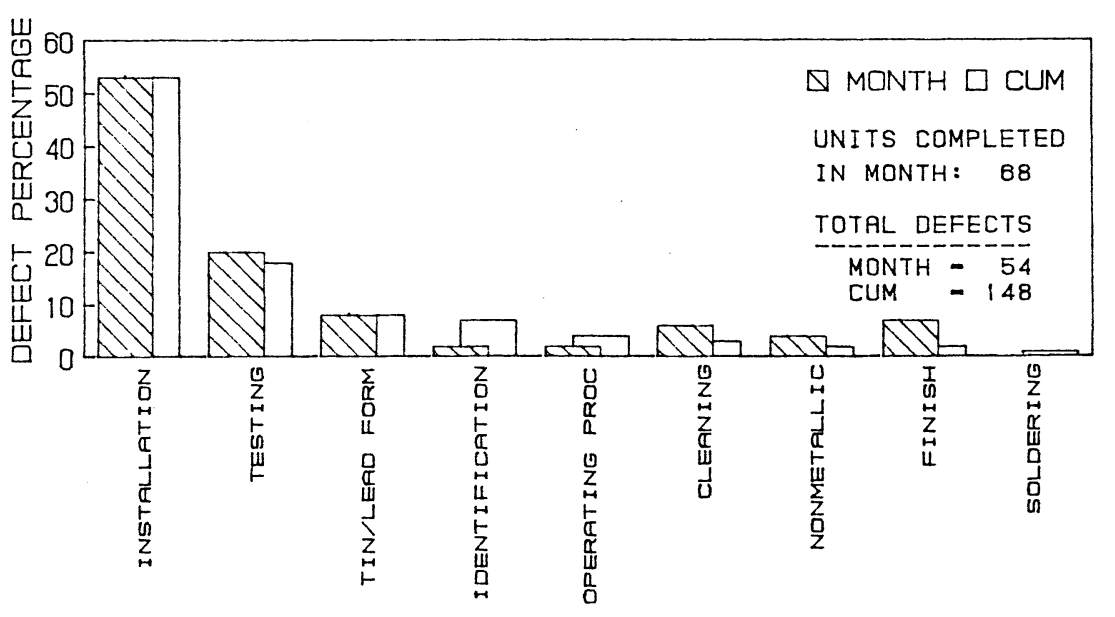

Fig. 4. Defect Distribution

My office is encouraging Navy contractors to collect and use these three types of defect tracking data in their programs, and we are monitoring the results. No new data collection is involved. Rather, current data are plotted in slightly different formats; the increase in manufacturing visibility is noteworthy.

\section{SUMMARY AND CONCLUSION}

The Navy's Best Practices generally deal with causing rather than measuring results. They involve intimate association with design and manufacturing disciplines. These proven disciplines evolve from the industrial community, and this makes them more acceptable to new users. Beginning in the 1970s with the F/A-18 Hornet aircraft (and earlier on selected subsystems) this approach has already brought far more reliable weapon systems to the fleet. The fundamental requirement for Best Practices to succeed is the commitment of top management in both the Government and its contractors.

\section{AUTHOR}

W. J. Willoughby Jr., Director; Reliability, Maintainability and Quality Assurance; Department of the Navy; Office of the Assistant Secretary of the Navy (Shipbuilding and Logistics); Washington, DC 20360-5000 USA.

Willis $\mathbf{J}$. Willoughby is the senior civilian for reliability in the Office of the Assistant Secretary of the Navy (Shipbuilding and Logistics). He is responsible for initiating policy, direction and counsel relating to all reliability, engineering, manufacturing, and quality assurance matters affecting naval material. Prior to "joining the Navy" Mr. Willoughby was the Director of Apollo Reliability, Quality and Safety for NASA's Office of Manned Space Flight, Apollo Program Office. His awards include the Presidential Rank Award of Distinguished Executive, and the President's Meritorious Executive Award. He earned a BS in Mechanical Engineering in 1952 from the University of South Carolina.

Manuscript TR87-136 received 1987 February 2; revised 1987 March 23.

IEEE Log Number 15955 